\title{
Simultaneous Ipsilateral Pediatric Fractures of the Elbow and Forearm Attending a Tertiary Care Hospital
}

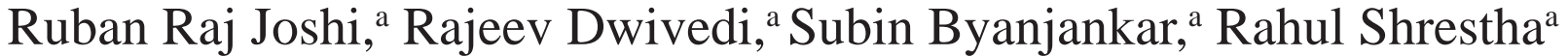

\begin{abstract}
:
Introduction: Ipsilateral supracondylar humerus and forearm fractures in the pediatric population are an uncommon injury associated with high-energy trauma. The incidence varies between $3 \%$ and $13 \%$. Our aim was to conduct a descriptive analysis on seventeen cases of children with floating elbow injuries who attended our institution and to review the literature relating to this topic. Methods: Between April 2013 to March 2016, data were obtained through the medical records. Children who had completely displaced supracondylar fractures of the humerus associated with ipsilateral forearm fracture were reviewed. All patients underwent operative reduction and percutaneous K-wire stabilization. At mean follow up of 12.9 months $(S D=3.9)$, all patients were assessed clinically and radiologically. The following variables were used: age, gender, side, mechanism, type of fracture, classification, treatment and complications. Results: Seventeen pediatric "floating elbow" cases that had operative management were identified. Twelve $(70.5 \% \%)$ were male and five $(29.4 \%)$ female. The mean age was $9.5(S D=2.1)$ years, ranging from six to 14 years. The left side was predominantly affected $(70.5 \%)$. The commonest injury mechanism was fall from a height (76.47\%). All the supracondylar fractures were Gartland type III. Majority of forearm fractures $(76.4 \%)$ were at distal meta diaphyseal region. Distal radius physeal fractures were diagnosed in three patients. Open fractures occurred in three cases (17.6\%). All supracondylar fractures were reduced and fixed using K-wires. There was one radial nerve, and three median nerve injury. Five patients had pin tract related complications. Fifteen (88.2\%) patients had good to excellent, two had fair in terms of modified Flynn criteria in last month follow up. All patients went on to radiographic union without secondary procedures. Conclusions: This uncommon injury in most cases, results from high-energy trauma. Early surgical treatment for both fractures is required in the form simultaneous reduction of the displaced forearm fracture followed by supracondylar fixation with K-wires. This provides not only stable fixation but also allows close observation for early sign and symptom of development of compartment syndrome.
\end{abstract}

Keywords: elbow $\bullet$ forearm $\bullet$ fracture $\bullet$ pediatric

a - Lecturer

Department of Orthopedics and Traumatology

Lumbini Medical College Teaching Hospital, Palpa, Nepal

Corresponding Author:

Dr. Ruban Raj Joshi

e-mail: rubanjoshi@hotmail.com

How to cite this article:

Joshi RR, Dwivedi R, Byanjankar S, Shrestha R. Simultaneous ipsilateral pediatric fractures of the elbow and forearm attending a tertiary care hospital. Journal of Lumbini Medical College. 2016;4(1):35-41. doi: 10.22502/jlmc.v4i1.85.

\section{INTRODUCTION:}

Elbow fracture together with fracture of the ipsilateral forearm represents severe upper limb injury in children. ${ }^{1}$ Stanitski and Micheli were the first to coined the term "floating elbow" to describe associations between such injuries in six cases. ${ }^{2}$ Such combination injuries are uncommon, with prevalence ranging from two to $13 \%$, and indicate higher-energy fracture. ${ }^{2,3}$

Such injury pattern is thought to have a high 
potential to develop compartment syndrome with potentially neurological sequela., ${ }^{4,5}$ However, the diagnosis of compartment syndrome in children can be challenging; there is inherent difficulty and poor reliability of a neurological examination in a pediatric patient. ${ }^{4,6,7}$

Various treatment options have been suggested for this type of injury such as primary closed reduction of both fracture and long arm cast application, olecranon pin traction and delayed long arm cast application, percutaneous pinning of supracondylar fracture and short arm cast application for forearm bone injury, or closed reduction and percutaneous pinning for both injuries. ${ }^{2,8,9,10}$ Templeton and Graham advocated fixation for forearm fractures was advantageous, as it enabled better monitoring of the neurovascular status of the affected limb and facilitated wound caring in the case of open fractures. ${ }^{11}$

Given the severity and rarity of this condition, as well as the scarcity of studies for an optimal management for such injuries, we reviewed our experience regarding the management of the floating elbow injury by early fracture reduction and operative stabilization.

\section{METHODS:}

The institutional review board approved the chart review for this study. All pediatric upper limb injuries with floating elbow who were operated in Lumbini Medical College Teaching Hospital between April 2013 to March 2016 were retrospectively reviewed. A total of 21 children with an elbow floating injury were evaluated. Four cases were excluded from the study: two had undisplaced and one had an incompletely displaced supracondylar fractures (Gartland/ Wilkins grade I and II) respectively. One patient was visiting from out of our district and was excluded from analysis due to lack of follow-up after surgery. Therefore, our study included 17 children with completely displaced supracondylar fractures associated with a forearm fracture. The variables studied were: demographic data, affected side, injury mechanism, type of fracture, associated complications, treatment administered, and complications secondary to the treatment. Final outcomes were evaluated according to modified Flynn criteria (Table 1). ${ }^{1}$

All the patients were posted for surgery next available day after temporary immobilization of the
Table 1: The modified Flynn classification (all measurements in degrees compared with normal un-injured limb; the largest deficit for movement in each plane is taken for assigning a clinical grade)

\begin{tabular}{lcccc}
\hline Grade & $\begin{array}{c}\text { Loss of } \\
\text { elbow } \\
\text { flexion/ } \\
\text { extension }\end{array}$ & $\begin{array}{c}\text { Loss of } \\
\text { forearm } \\
\text { pronation/ } \\
\text { supination }\end{array}$ & $\begin{array}{c}\text { Loss of } \\
\text { wrist }\end{array}$ & $\begin{array}{c}\text { Change in } \\
\text { carrying } \\
\text { angle }\end{array}$ \\
\hline Excellent & $0-5$ & $0-15$ & $0-15$ & $0-5$ \\
Good & $6-10$ & $16-30$ & $16-30$ & $6-10$ \\
Fair & $11-15$ & $31-45$ & $31-45$ & $11-15$ \\
Poor & $>15$ & $>45$ & $>45$ & $>15$ \\
\hline
\end{tabular}

limb with splint and analgesics. Compound fractures were managed on the same day of presentation at emergency department with debridement, fracture fixation and intravenous antibiotics.

All the operative procedures were performed in operating room under general anesthesia. At first, forearm fracture were reduced and stabilized before supracondylar fracture. A first K-wire was inserted through or just proximal to radial styloid process to avoid physis and advanced proximally medially to opposite cortex across the fracture. A second K-wire was passed just medial to Lister tubercle to volar and lateral side. Then the supracondylar fracture was reduced in standard maneuver and stabilized with either two divergent lateral pins or with an additional pin from medial epicondyle, depending upon the degree of comminution and instability. Sheer consideration was taken during inserting the medial pin to protect the ulnar nerve. All the K-wires were bend outside the skin for easy removal at clinic in 4-6 weeks time. The operated limb was splinted for four to six weeks. Patients were followed, at a minimum, until all fractures were healed, full range of motion was restored, and all complications had resolved. The range of movement at the elbow and wrist and the carrying angle were measured with a goniometer, and all measurements were compared to the contralateral normal limb. The outcome was graded according to a clinical scale proposed by Flynn modified to include assessment of the wrist (Table 1). ${ }^{1}$ The elbow and forearm were assessed separately, and the lower of the two results was taken as the result for that limb.

\section{RESULTS:}

The study identified 17 patients who met inclusion criteria and had appropriate follow-up. Average age was $9.5(S D=2.1)$ with a range 6-14 yr while the median was nine years. Twelve patients 
$(70.5 \%)$ were male and five $(29.4 \%)$ were female. The left side was more affected $(70.5 \%)$. All but one of the injuries were the result of indirect violence due to a fall. The commonest mode of injury was fall from a height, in 13 patients (76.47\%), mainly from fruit trees. Three patients sustained the injury from fall at ground level and one child sustained a motor vehicle accident (Tables 2 ). The mean followup time was 12.9 months ( $S D=3.9$ ).

Three of the elbow injuries were open fractures and were managed by debridement and stabilization with K-wires. Four patients had a neurological injury, and two had pink pulseless limb. The circulation returned after immediate reduction and stabilization. Sixteen supracondylar fractures were Gartland/ Wilkins grade III extension injuries and one was flexion variant. Fifteen were treated by closed reduction and percutaneous K-wire stabilization. In two cases (17.6\%), it was necessary to perform an open reduction of the elbow (Patient 3 and 11) and mini open reduction for a forearm fracture in one case (Fig 3, Table 3).

Thirteen children had fracture of the distal meta-diaphyseal forearm and one had forearm shaft fracture. All were operated by closed reduction and K-wire fixation except one who had cast immobilization. One patient had intramedullary rush pin fixation of both radius and ulna shaft fracture followed by a long arm slab (Fig 3). In three, the physis of lower radius was involved and all were treated by closed reduction and K-wire fixation. All K-wires were cut and left outside the skin after bending the tip to prevent migration.

Fifteen patients (88.2\%) had a good or excellent outcome at the final follow-up and two patients had a fair result (Table 4). One patient who underwent reduction for Gustilo I flexon type supracondylar fracture with absent radial pulse had loss of reduction and required a re-manipulation and an additional medial K-wire fixation (Patient 11). A second patient after a Gustilo II supracondylar fracture required a secondary closure. There were three cases with pin track infections and two loosening of distal radius pins. No patient had a change in the carrying angle at the elbow of more than $8^{\circ}$. The neurological deficits of four patients had resolved by last follow-up, typically by 3-6 months postoperatively. Radiographs showed no evidence of physeal arrest in those cases where K-wires had transfixed the growth plate of the distal radius (Fig. 1 and 2). A good radiographic union was achieved in all cases without need for secondary procedures.

\section{DISCUSSION:}

The gender and side predominance that we found is corroborated by the literature. ${ }^{2,5}$ The commonest mechanism of fall from a height, especially from trees, emphasizes that association of ipsilateral humerus and forearm result from more violent episodes of trauma in most cases, given that the force is not totally dissipated through the first fracture alone. ${ }^{5}$

Table 2: Patient details $(n=17)$

\begin{tabular}{lc}
\hline Sex & $\boldsymbol{n}$ \\
\hline Male & 12 \\
Female & 5 \\
Side & \\
$\quad$ Right & 6 \\
Left & 11 \\
Injury Mechanism & 13 \\
Fall from height & 3 \\
Other falls (playing,bicyle) & 1 \\
\hline RTA &
\end{tabular}

Table 3: Injury details

\begin{tabular}{|cc}
\hline Forearm fractures: & $\boldsymbol{n}$ \\
\hline Closed & 17 \\
\hline Open & 0 \\
\hline Both bones: & 14 \\
\hline Distal third & 13 \\
\hline Proximal third & 1 \\
\hline Radius alone : & 3 \\
\hline Salter Harris Type: & 2 \\
\hline II & 1 \\
\hline I & \\
\hline Supracondylar fracture: & 14 \\
\hline Closed & 3 \\
\hline Open & 2 \\
\hline$\quad$ Gustilo I & 1 \\
\hline Gustilo II & 16 \\
\hline Classification: & 1 \\
\hline Extension Type III & 2 \\
\hline Flexion & 3 \\
\hline Associated injury: & \\
\hline Absent Radial pulse & \\
\hline Median nerve injury & \\
\hline Radial nerve injury & 1 \\
\hline
\end{tabular}


Table 4: Treatment and assessment outcomes in 17 patients

\begin{tabular}{|c|c|c|c|c|c|c|c|c|}
\hline Case & Treatment* & $\begin{array}{l}\text { Soft tissue } \\
\text { injury }\end{array}$ & Assoc. injury & $\begin{array}{l}\text { Loss of } \\
\text { elbow } \\
\text { flexion } \\
\text { extension }\end{array}$ & $\begin{array}{l}\text { Loss of } \\
\text { forearm } \\
\text { supination } \\
\text { pronation }\end{array}$ & $\begin{array}{l}\text { Loss of } \\
\text { wrist } \\
\text { flexion } \\
\text { extension }\end{array}$ & $\begin{array}{c}\text { Change } \\
\text { of } \\
\text { carrying } \\
\text { angle }\end{array}$ & Results** \\
\hline 1 & CRPP & & & 5 & 15 & 0 & 0 & Excellent \\
\hline 2 & CRPP & & Median nerve injury & 5 & 10 & 10 & 5 & Excellent \\
\hline 3 & $\begin{array}{l}\text { Debridement, ORIF } \\
\text { + CRPP radius }\end{array}$ & Gustilo II & & 10 & 20 & 15 & 8 & Good \\
\hline 4 & CRPP & & & 0 & 0 & 0 & 0 & Excellent \\
\hline 5 & CRPP & & Absent radial pulse & 5 & 0 & 0 & 0 & Excellent \\
\hline 6 & CRPP & Gustilo I & & 0 & 10 & 15 & 0 & Excellent \\
\hline 7 & CRPP & & & 15 & 10 & 20 & 6 & Good \\
\hline 8 & CRPP & & & 0 & 9 & 5 & 4 & Excellent \\
\hline 9 & MUA cast & & Median nerve injury & 9 & 10 & 25 & 5 & Good \\
\hline 10 & CRPP & & & 0 & 8 & 14 & 0 & Excellent \\
\hline 11 & ORPP + CRPP & Gustilo I & Absent radial pulse & 15 & 10 & 40 & 8 & Fair \\
\hline 12 & CRPP & & & 0 & 10 & 0 & 0 & Excellent \\
\hline 13 & CRPP & & Radial nerve injury & 8 & 10 & 20 & 8 & Good \\
\hline 14 & CRPP & & & 0 & 8 & 0 & 0 & Excellent \\
\hline 15 & $\begin{array}{l}\text { Mniopen + Intra- } \\
\text { medullary pinning }\end{array}$ & & $\begin{array}{c}\text { Anterior interosseous } \\
\text { nerve injury }\end{array}$ & 15 & 45 & 35 & 7 & Fair \\
\hline 16 & CRPP & & & 0 & 12 & 0 & 5 & Excellent \\
\hline 17 & CRPP & & & 0 & 10 & 0 & 0 & Excellent \\
\hline
\end{tabular}

* Closed reduction and percutaneous K-wire fixation of both elbow and forearm injuries unless stated

** Outcome graded according to modified Flynn criteria (Table 1)
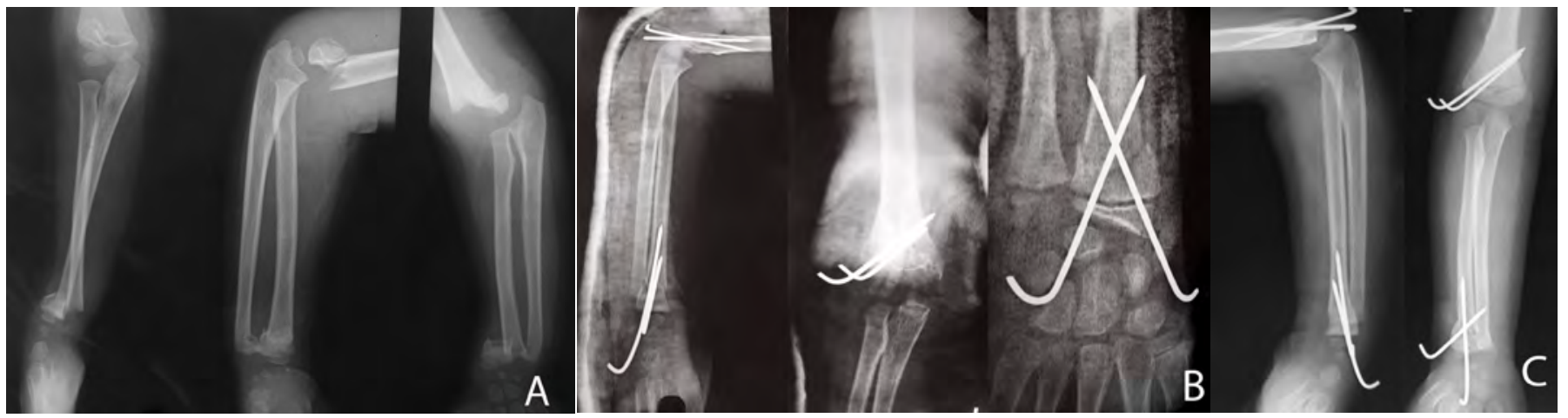

Fig 1:

A. Preoperative radiographs of 7 yrs girl with

floating elbow injury;

B. Postoperative X-ray after closed reduction \&

pinning;

C. 6 weeks radiographs showing radiological union;

D. Final excellent clinical outcome.

(Color picture available online)

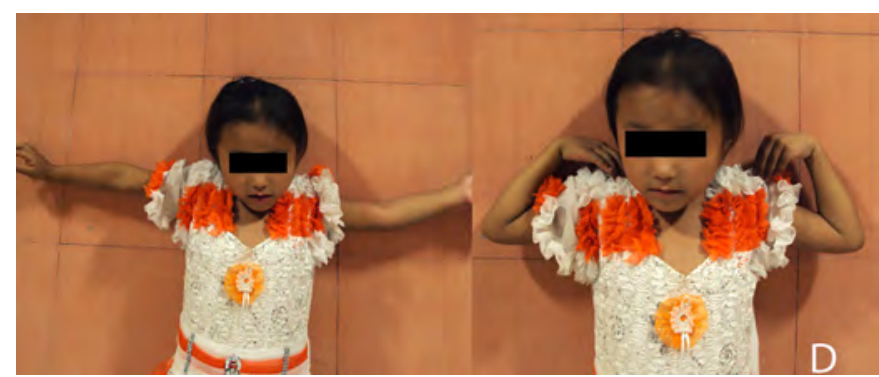




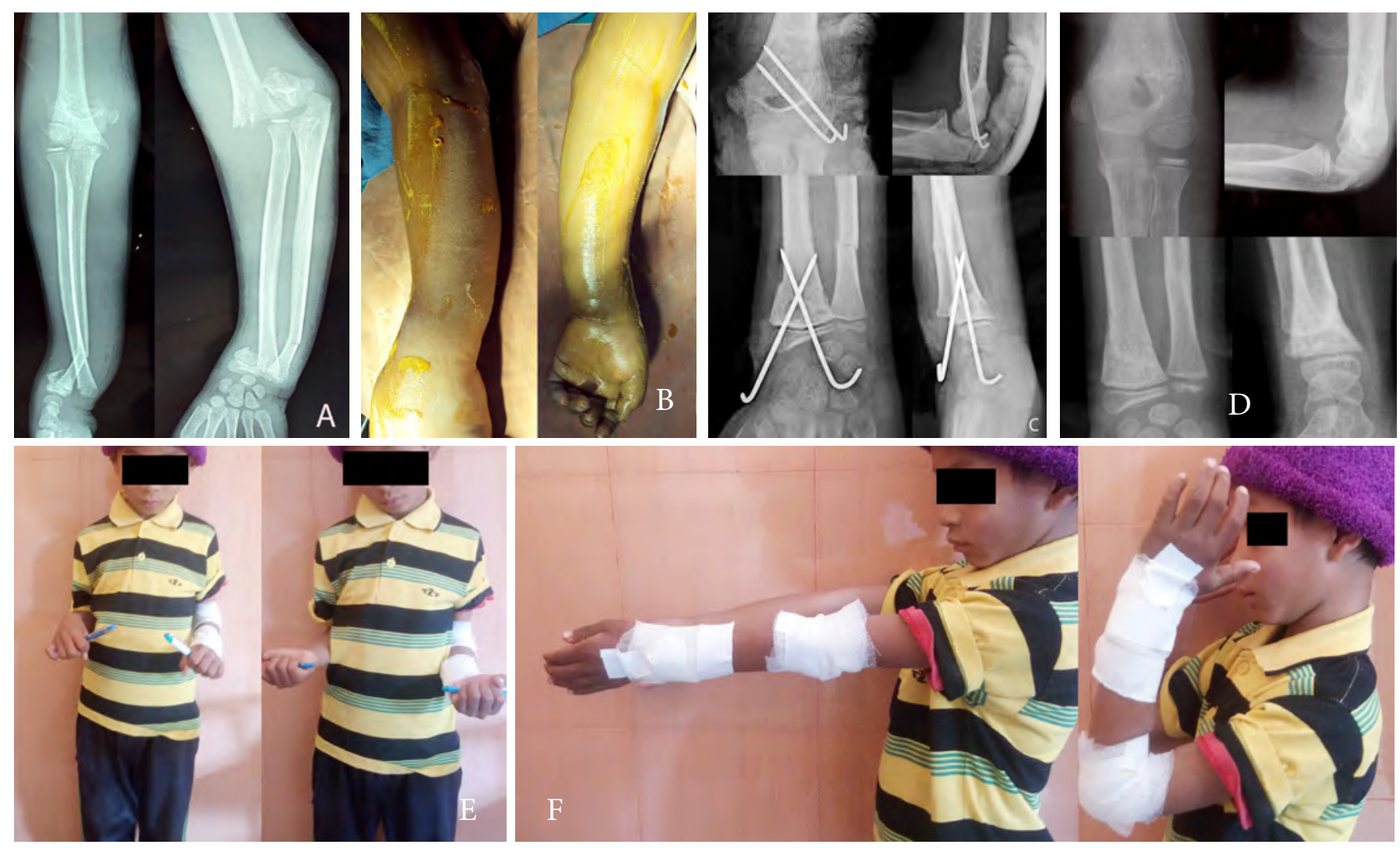

Fig 2: A. Radiographs of a 9-year-old boy with open (Gustilo I) displaced supracondylar fracture and closed distal radius and ulna fracture after a fall from tree. B. The deformed limb; C. After closed reduction, K-wire fixation of the elbow distal radius. D. After removal of K-wires at 8 weeks. E,F. Final excellent outcome according to modified Flynn criteria.
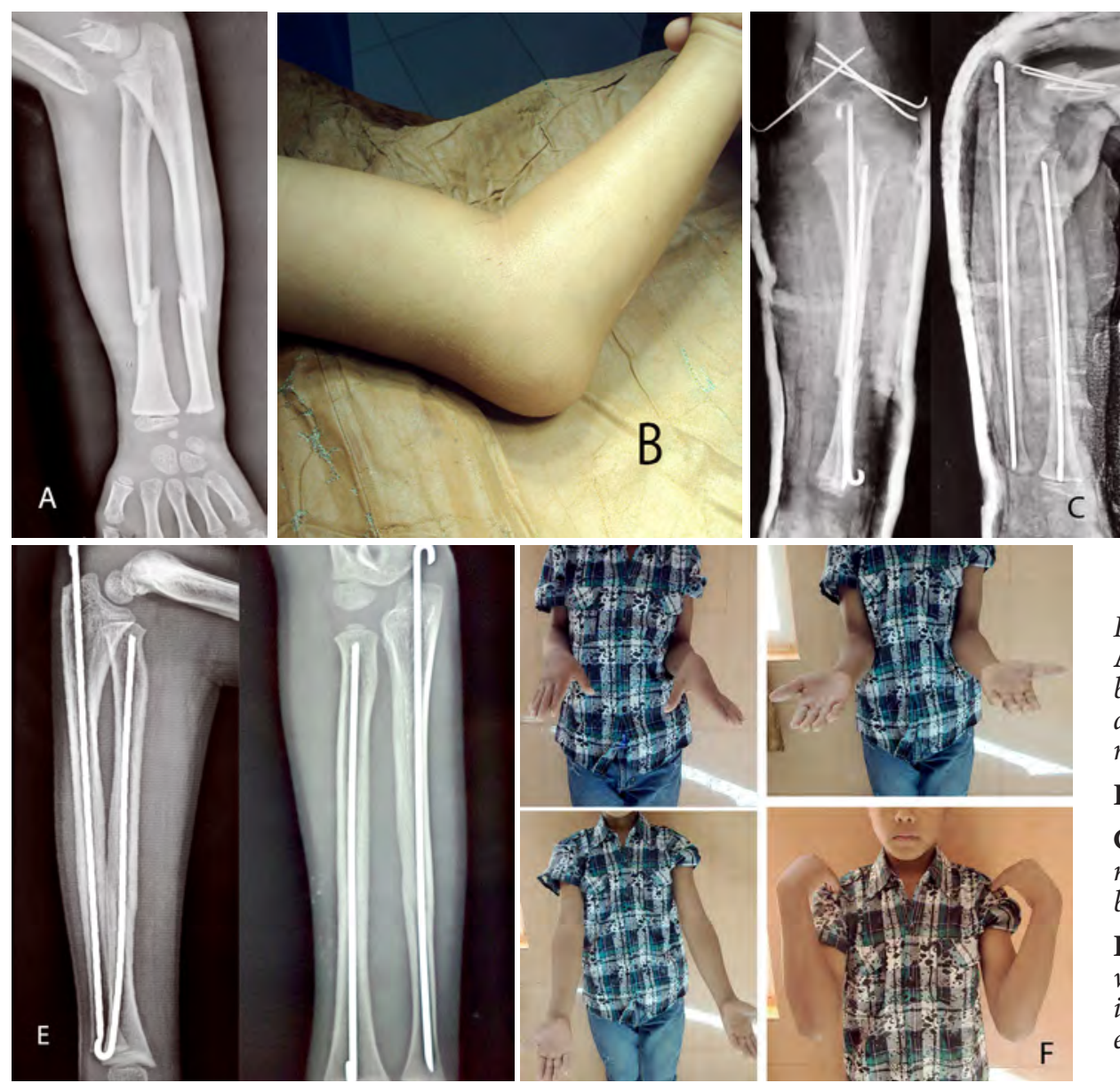

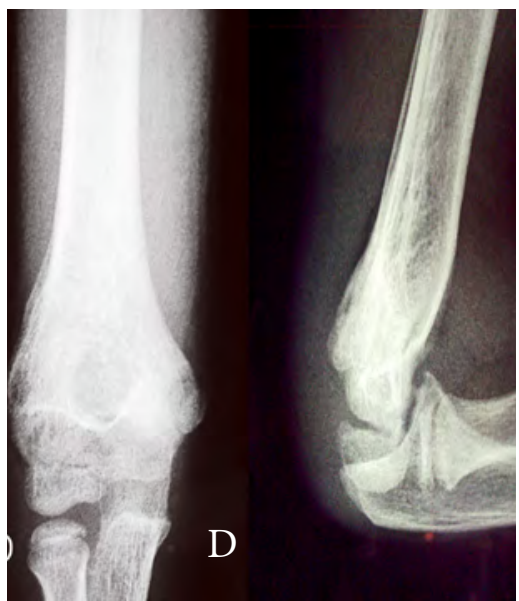

Fig 3:

A. Forearm radiograph of the 10 year boy with displaced extension supracondylar fracture with ipsilateral fracture radius ulna shaft;

B. Pre-operative deformed limb;

C. Postoperative radiographs with rush nail fixation forarm with pinning of elbow fracture;

D,E,F. Four months postop radiographs with ongoing remodeling of both injuries. Final clinical outcome with excellent result. 
The forearm fracture most frequently found were of distal radius fractures, which is in agreement with the current literature. ${ }^{2,5}$ It has been suggested that if the forearm fracture occurs proximal to the junction of the middle and distal third, then the lever arm of the proximal forearm is too short to generate the force required to produce a humeral fracture. ${ }^{11}$ The occurrence of a supracondylar fracture with a proximal forearm injury is an indicator of the greatest traumatic force in patients with a floating elbow injury. ${ }^{1}$ In our study, one case (patient 15 , Fig 3 ) had a radius ulna shaft fracture. The incidence of open fractures (17.6\%) and neurological injury (23.5\%) is much higher than those reported for isolated supracondylar fractures. In a meta-analysis of 61 studies of 7,212 supracondylar fractures, Wilkins reported open injuries in 1\% and neurological injury in $7.7 \% .{ }^{12}$ In a series of eight cases of floating elbow, Templeton and Graham reported two occurrences of lesions in the median nerve, one in the anterior interosseous nerve and one in the ulnar nerve. According to these authors, this incidence was high because of the severity of the trauma and the resultant high-energy injury. ${ }^{11}$

In the present study, two (11.7\%) of the supracondylar fractures of the humerus (patient 3 and 11) required open reduction. This contradicts finding of Harrington et al. that open reduction is performed more often on patients with floating elbow due to fractures with large displacements because of the violence of the trauma involved. There is an increased likelihood that the spike of the proximal humeral fragment will become 'buttonholed' through the anterior soft tissues, rendering the fracture irreducible by closed manipulation. ${ }^{1}$

Treatment of displaced supracondylar fracture has evolved from non operative management with closed reduction and posterior back slab, olecranon traction to closed reduction , and percutaneous $\mathrm{K}$ wire fixation. Various fixation techniques of $\mathrm{K}$ wire have been described in literature for better biomechanical stability and to decrease chance of potential iatrogenic nerve injury. ${ }^{13}$ In our institute, the preferred method consisted of using lateral two divergent $\mathrm{K}$-wire at an angle of $45^{\circ}$. This mode of stabilization has produced excellent results, without any reports of neural lesions. ${ }^{16}$ In the present study, none of the supracondylar fractures of the humerus were treated non operatively.

Likewise, distal both bone forearm fractures are mostly treated by closed reduction and percutaneous K-wire fixation to prevent redisplacement of the fracture in the cast and it would enable better monitoring of the neurovascular status of the affected arm. ${ }^{14}$ This would facilitate caring for skin wounds, in the case of compound fractures, and would have lower incidence of loss of reduction, compared with conservative treatment. The incidence of redisplacement is reported up to $7 \%$ to $25 \%$ by various studies. ${ }^{15}$ Roposch A. et al. reported redisplacement in three cases among 18 patients with forearm fractures treated with cast while none in 29 cases managed with percutaneous pinning. ${ }^{18}$ Fifteen (88.2\%) out of seventeen underwent closed reduction and percutaneous fixation and none had redisplacement.

Williamson DM et al. managed the supracondylar fracture by traction or manipulative reduction and percutaneous pinning and the forearm fractures by reduction and casting, but is associated with prolonged hospitalization and hence increased financial and psychological burden. ${ }^{17}$ Because of higher incidence of compartment syndrome associated with floating elbow, reported as high as up to $33 \%$, various authors have recommended pinning for both fracture which allows close observation of neurovascular structure and also reduces chances of redisplacement of fracture in cast or slab. ${ }^{5}$ Ring D. et al. found two patients with compartment syndrome and four patients with incipient compartment syndrome among ten patients treated with closed reduction and cast immobilization whereas none among those treated with percutaneous pinning of the fractures. ${ }^{5}$

The present series found one case (patient 13) of impending compartment syndrome which was treated by emergency closed reduction and pinning, followed by close monitoring of the forearm.

Priority of reduction of stabilization of supracondylar fracture or forearm injury first varies among authors though no definitive study has been done in terms of outcome and complications. Those who advocate initial supracondylar fracture fixation assume that maintenance of reduction, access to the limb for neurovascular monitoring, dressings, and closure of open fractures may be difficult if the forearm fracture is treated first. ${ }^{8,11}$ In our patients, we preferred treating the forearm fracture first, as forearm soft tissue gets more injured during traction and manipulation during reduction of supracondylar fracture and can increase probability of compartment syndrome. Also, pronation or supination is required 
to maintain reduction of supracondylar fracture will be secured and easy if we reduce and stabilize forearm fracture first as initial maneuver. Similar preference of order of reduction for both component injury was asserted by Shrestha D. et al. ${ }^{19}$ Infection along the paths of the K-wires were found in five patients (29.4\%), and was resolved by oral antibiotics and removal of the wires. In present study, a good to excellent results obtained in fifteen patients $(88.2 \%)$ as assessed by modified Flynn criteria is comparable to a study by Harrington P. et al. (83\% good or excellent). ${ }^{1}$

\section{REFERENCES:}

1. Harrington P, Sharif I, Fogarty EE, Dowling FE, Moore DP. Management of the floating elbow injury in children. Simultaneous ipsilateral fractures of the elbow and forearm. Arch Orthop Trauma Surg. 2000;120(3-4):205-8.

2. Stanitski CL, Micheli LJ. Simultaneous ipsilateral fractures of the arm and forearm in children. Clin Orthop Relat Res. 1980 Nov-Dec;(153):218-22.

3. Piggot J, Graham HK, McCoy GF. Supracondylar fractures of the humerus in children. Treatment by straight lateral traction. J Bone Joint Surg Br. 1986 Aug;68(4):577-83.

4. Blakemore LC, Cooperman DR, Thompson GH, Wathey C, Ballock RT. Compartment syndrome in ipsilateral humerus and forearm fractures in children. Clin Orthop Relat Res. 2000 Jul;(376):32-8.

5. Ring D, Waters PM, Hotchkiss RN, Kasser JR. Pediatric floating elbow. J Pediatr Orthop. 2001;21:456-9.

6. Matsen FA III, Veith RG. Compartmental syndromes in children. J Pediatr Orthop. 1981;1:33-41.

7. Noonan KJ, McCarthy JJ. Compartment syndromes in the pediatric patient. J Pediatr Orthop. 2010;30:S96-S101. doi:10.1097/BPO.0b013e3181d07118

8. Biyani A, Gupta SP, Sharma JC. Ipsilateral supracondylar fracture of the humerus and forearm bones in children. Injury. 1989;20(4):203-7.

9. Tabak AY, Celibi L, Muratli HH, Yagmurlu MF, Aktekin $\mathrm{CN}$, Biçimoglu A. Closed reduction and percutaneous fixation of supracondylar fracture of the humerus and ipsilateral fracture of the forearm in children. J Bone Joint Surg Br. 2003;85:1169-72

10. Suresh SS. Management of "floating elbow" in children. Indian J Orthop. 2007 Oct-Dec; 41(4): 386-9.

11. Templeton PA, Graham HK. The 'floating elbow' in children. Simultaneous supracondylar fractures of the

\section{CONCLUSIONS:}

Floating elbow is a severe injury in pediatric traumatology and mostly results from high-energy trauma. Surgical treatment is recommended for both components. Simultaneous closed reduction of the ipsilateral displaced forearm fracture followed by supracondylar fixation with K-wires provides not only stable fixation but also allows close observation for early detection of compartment syndrome.

humerus and of the forearm in the same upper limb. J Bone Joint Surg Br. 1995 Sep;77(5):791-6.

12. Wilkins KE. Fractures and dislocations of the elbow region. In: Rockwood CA,Wilkins KE, King RE. (eds.). Fractures in children. New York: JB Lippincott; 1991. p.509-828

13. Pandey S, Shrestha D, Gorg M, Singh GK, Singh MP. Treatment of supracondylar fracture of the humerus (type IIB and III) in children: A prospective randomized controlled trial comparing two methods. Kathmandu Univ Med J (KUMJ). 2008;6(23): 310-8.

14. Shrestha D, Dhoju D, Parajuli N, Dhakal G, Shrestha R. Management of pediatric displaced distal metaphyseal forearm fracture: Comparison between cast immobilization and percutaneous Kirschner wire fixation. Nepal Orthopedic Association Journal (NOAJ). 2011;2(1):1-6.

15. Voto SJ, Weiner DS, Leighley B. Redisplacement after closed reduction of forearm fractures in children. J Pediatr Orthop. 1990 Jan-Feb;10(1):79-84.

16. Terra DL, Santos MHB, Malheiros DS, Lima CLFA, Cunha FM. Nova abordagem no tratamento da fratura supracondilar do úmero, instável, em crianças e adolescentes. Rev Bras Ortop. 2005;40(1/2):42-51.

17. Williamson DM, Cole WG. Treatment of ipsilateral supracondylar and forearm fractures in children. Injury. 1992;23:159-61.

18. Roposch A, Reis M, Molina M, Davids J, Stanley E, Wilkins K et al. Supracondylar fractures of the humerus associated with ipsilateral forearm fractures in children: a report of forty seven cases. J Pediatr Orthop. 2001 MayJun;21(3):307-12.

19. Dhoju D, ShresthaD, Parajuli N, Dhakal G, Shrestha R. Ipsilateral supracondylar fracture and forearm bone injury in children: a retrospective review of thirty one Cases. Kathmandu Univ Med J (KUMJ). 2011 Apr-Jun;9(34):11-6. 